\title{
Epidemiological and Clinical Profiles of Maternal Deaths in Cotonou
}

\author{
Aboubakar Moufalilou ${ }^{1, ~}$, Obossou Achille Awade ${ }^{2}$, Ogoudjobi Mathieu', \\ Lokossou Symphorose $^{1}$, Dangbemey Patrice ${ }^{1}$, Tshabu-Aguemon Christiane ${ }^{1}$, \\ Tonato-Bagnan Angeline ${ }^{1}$, Denakpo Lewis Justin ${ }^{1}$ \\ ${ }^{1}$ Mother and Child Department/Faculty of Health Sciences, University of Abomey-Calavi, Cotonou, Benin \\ ${ }^{2}$ Faculty of Medicine, University of Parakou, Parakou, Benin
}

\section{Email address:}

moufaliloua@yahoo.fr (A. Moufalilou)

${ }^{*}$ Corresponding author

\section{To cite this article:}

Aboubakar Moufalilou, Obossou Achille Awade, Ogoudjobi Mathieu, Lokossou Symphorose, Dangbemey Patrice, Tshabu-Aguemon Christiane, Tonato-Bagnan Angeline, Denakpo Lewis Justin. Epidemiological and Clinical Profiles of Maternal Deaths in Cotonou. Journal of Gynecology and Obstetrics. Vol. 9, No. 5, 2021, pp. 145-149. doi: 10.11648/j.jgo.20210905.12

Received: August 24, 2021; Accepted: September 8, 2021; Published: September 23, 2021

\begin{abstract}
Introduction: Due to its high frequency, maternal mortality remains a major public health problem, especially in developing countries. Therefore, it is important to establish the epidemiological and clinical profiles of women who died in order to adapt the means to fight maternal mortality. The objective was to study maternal deaths in three university associated hospitals in Benin from 2015 to 2020. Materials and methods: This was a descriptive cross-sectional and retrospective study. Were included women who died during pregnancy or within the 42 days after delivery from January 2015 to September 2020 in the maternity units of National and University Associated Hospital-Hubert Koutoukou Maga (CNHU-HKM), University Associated Hospital of Mother and Child (CHU-MEL) and Army training hospital- University-associated hospital (HIA-CHU). Results: In total, 575 cases of maternal deaths were recorded and the majority at the maternity unit of CNHU-HKM (79.30\%). The average age was $29.1( \pm 6.5)$ years with extremes of 14 and 45 years. The majority of death was observed in women aged 25 to 29 years. The deceased women were most often pauciparous (33.57\%), referred (78.96\%), admitted in poor general condition (58.43\%) and were in the postpartum period (80.17\%) at the time of death. The main causes of maternal death were: haemorrhage $(32.87 \%)$, hypertensive disorders during pregnancy $(22.22 \%)$, infections $(8.35 \%)$ and abortion $(5.74 \%)$. Conclusion: Maternal mortality remains high in our health facilities. It mainly affects populations with modest socio-economic conditions. The reduction of maternal mortality requires an improvement in the socio-economic conditions of the population, in the technical platform and in the referral modalities.
\end{abstract}

Keywords: Maternal Deaths, Epidemiology, Clinical, Aetiologies, Benin

\section{Introduction}

Maternal mortality remains a major public health problem despite all efforts to fight it. In 2015, 303,000 women died during or after pregnancy or childbirth, i.e. approximately 830 women died every day worldwide. [1]. In 2017 nearly 300,000 women died from complications during pregnancy or childbirth. More than $90 \%$ of them lived in low- and middleincome countries [2]. Sub-Saharan Africa alone accounts for more than half of all maternal deaths occuring in poor countries, even though the maternal mortality rate there has fallen considerably since 1990. In Benin, maternal mortality has fallen from 498 maternal deaths per 100,000 live births in 1996 to 351 in 2014 and 391 in 2018 [3]. These figures are alarming as the right to life is a fundamental human right.

An effective fight against maternal mortality implies a good knowledge of the women who die in terms of age group, profession, origin, on the one hand, and the clinical pictures they present on the other

This work aims to study the epidemiological and clinical profiles of maternal deaths in three hospitals in Benin. 


\section{Materials and Method}

This was a retrospective descriptive study conducted over a period of 5byears and 9 months from, 1 January 2015 to 30 September 2020 in the maternity units of three university associated hospitals. All deaths occurring during pregnancy, delivery or within 42 days after its termination, for a cause related to pregnancy, delivery or postpartum, were included. A non-probabilistic method has been used. Recruitment was exhaustive, taking into account all maternal death records meeting the inclusion and non-inclusion criteria. The independent variables were socio-demographic, clinical and etiological. Data were collected from medical records, registers and operative reports using an individual survey form and smartphones on which the Kobocollect software was installed for data recording. The data collected was processed with the EPI INFO software version 7.2. Data analysis was done using tables and curves established by processing the data with Excel and Word software.

\section{Results}

\subsection{Frequency}

During the study, 575 cases of maternal deaths were recorded for all three hospitals. Table 1 shows the distribution of maternal deaths during the study period by hospital. The majority of maternal deaths were recorded at the maternity unif of CNHUHKM with a proportion of $79.30 \%$.

Table 1. Distribution of maternal deaths by hospital (CNHU-HKM, CHUMEL, HIA-CHU, 2015-2020).

\begin{tabular}{lll}
\hline Hospital & number $(\mathbf{N})$ & Percentage (\%) \\
\hline CNHU-HKM & 456 & 79,30 \\
CHU-MEL & 113 & 19,65 \\
HIA-CHU & 6 & 1,04 \\
Total & 575 & 100,00 \\
\hline
\end{tabular}

\subsection{Epidemiological Profil}

The average age was $29.1( \pm 6.5)$ years with extremes of 14 and 45 years. The majority of the deceased women lived in urban areas $(66.43 \%)$ and were traders $(40.00 \%)$. The majority of the spouses worked as manual labourers $(23.65 \%)$. Deaths were more frequent among women aged 25 to 29 years.

\subsection{Clinical Profil}

Sickle cell disease and HIV were the most common medical histories. Considering the most represented age group, 25-29 years, the pauciparous were the most affected.

Maternal deaths occurred much more often in referred women $(78.96 \%)$. For the 165 cases for which the type of transport was specified, the transport was not medicalised in $64.84 \%$ of cases.

The most frequent reasons for admission were haemorrhage (23.48\%) followed by eclampsia (16.87\%).

In $41.56 \%$ of the women who died, functional signs were associated. Genital bleeding and pelvic pain were the most common signs.

The general condition was considered alered on admission in $58.43 \%$ of cases. However, $89.05 \%$ of the women who died were conscious.

Singleton pregnancies predominated with a proportion of $67.13 \%$.

The most frequent diagnosis at entry was eclampsia with a proportion of $17.57 \%$; followed by post partum haemorrhage with a proportion of $17.39 \%$.

The distribution of maternal deaths according to the diagnosis of entry is presented in Table 2 .

Table 2. Distribution of maternal deaths by diagnosis at entry (CNHU-HKM, CHU-MEL, HIA-CHU, 2015-2020).

\begin{tabular}{lll}
\hline Diagnosis at entry & Number $\mathbf{( N )}$ & Percentage (\%) \\
\hline Anemia & 37 & 6,43 \\
Fetal asphyxia & 2 & 0,35 \\
Abortion & 13 & 2,26 \\
Chorioamnionitis & 3 & 0,52 \\
Coma & 15 & 2,61 \\
vaso-occlusive crisis & 14 & 2,43 \\
Eclampsia & 101 & 17,57 \\
Endométritis & 7 & 1,22 \\
shock & 13 & 2,26 \\
ectopic pregnancy & 7 & 1,22 \\
Haemoperitoneum & 6 & 1,04 \\
Post partum haemorrhage & 100 & 17,39 \\
abruptio placenta & 22 & 3,83 \\
Gravidic HTA & 6 & 1,04 \\
Premature delivery threats & 12 & 2,09 \\
In utero fetal death & 10 & 1,74 \\
Acute Pulmonary oedem & 4 & 0,70 \\
Intra uterine growth restriction & 9 & 1,57 \\
Placenta Prævia & 11 & 1,91 \\
Pneumonia & 6 & 1,04 \\
Pré éclampsia & 55 & 9,57 \\
Premature rupture of Membranes & 4 & 0,70 \\
Uterine rupture & 24 & 4,17 \\
Sepsis & 21 & 3,65 \\
Delivery Labor & 19 & 3,30 \\
Others* & 54 & 9,39 \\
Total & 575 & 100,00 \\
\hline & & \\
\hline
\end{tabular}

Most of the women who died were admitted in the antepartum period with a proportion of $54.61 \%$. However, the majority of maternal deaths occurred in the postpartum period with a proportion of $80.17 \%$.

\subsection{Aetiologies}

Haemorrhage was the most frequent direct cause of death with a proportion of $32.87 \%$ followed by hypertension and its complications with $25.22 \%$ of cases. Among the deaths due to haemorrhage, immediate postpartum haemorrhage was the most frequent with a proportion of $57.67 \%$. The most frequent cause of death by hypertension was eclampsia with a proportion of $66.21 \%$.

In terms of indirect causes, anaemia was the most frequent with a proportion of $5.39 \%$. Table 3 shows the distribution of maternal deaths by cause.

Among the women who died from vaginal delivery, the 
cause of death was mainly haemorrhage; and among those who died from vaginal delivery, the cause of death was mainly hypertension.
The distribution of maternal deaths according to cause of death and route of delivery is shown in Figure 2.

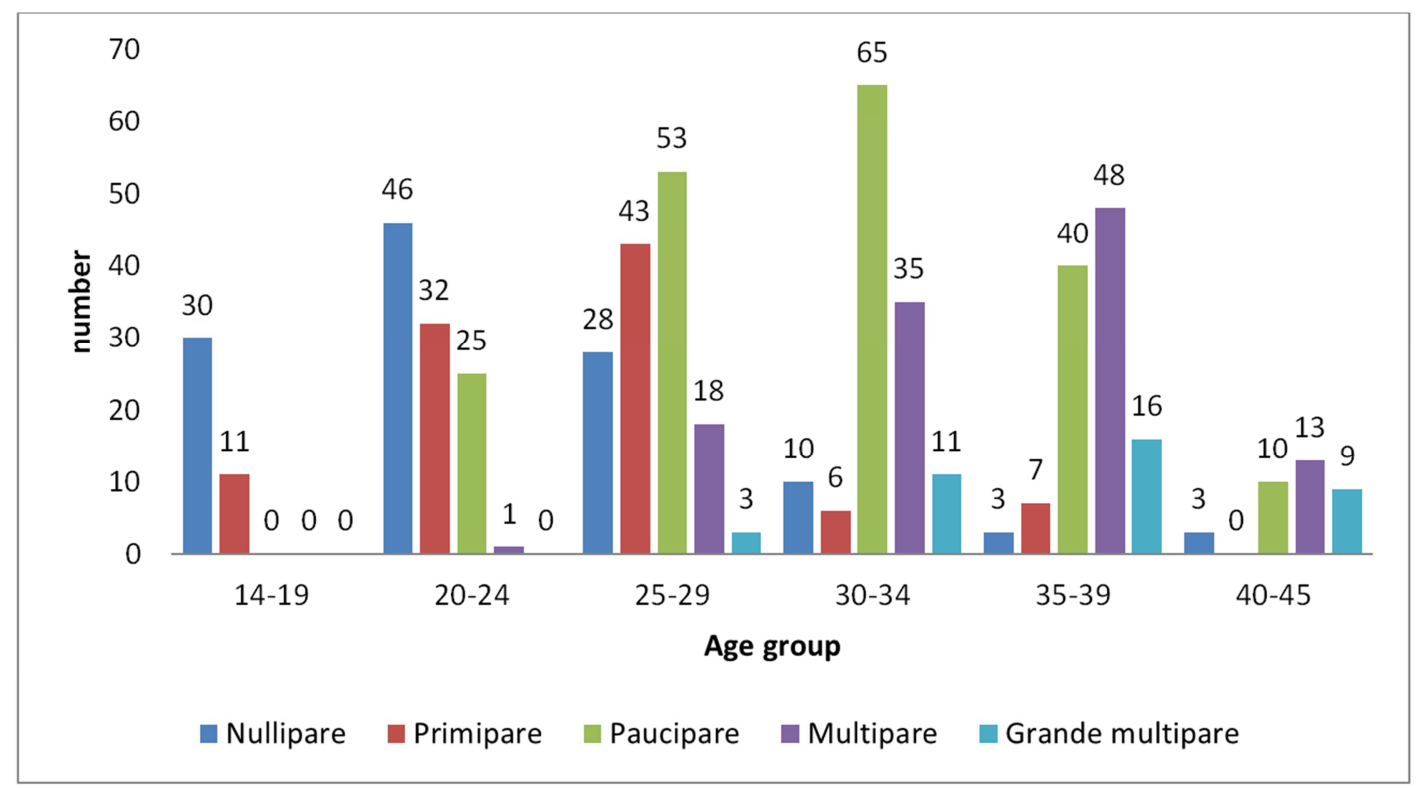

Figure 1. Distribution of maternal deaths by age and parity (CNHU-HKM, CHU-MEL, HIA-CHU, 2015-2020).

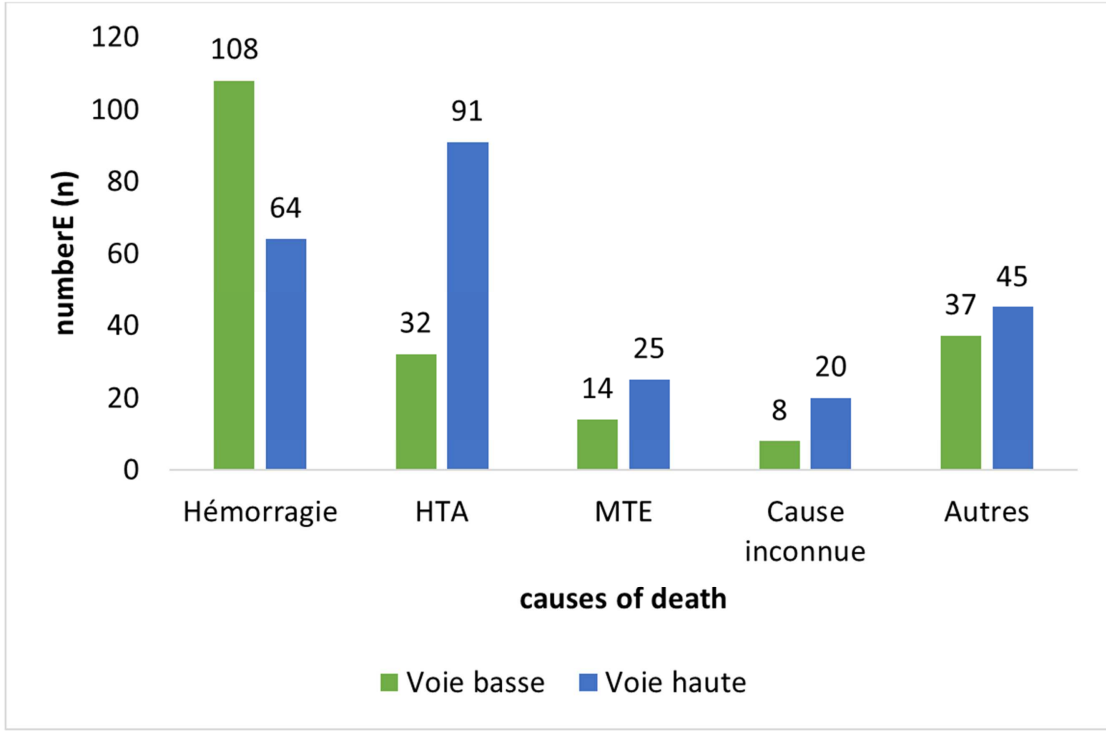

Figure 2. Distribution of maternal deaths by age and parity (CNHU-HKM, CHU-MEL, HIA-CHU, 2015-2020).

Table 3. Distribution of maternal deaths by cause of death (CNHU-HKM, CHU-MEL, HIA-CHU, 2015-2020).

\begin{tabular}{lll}
\hline Cause of death & Number $(\mathbf{N})$ & Percentage (\%) \\
\hline Direct aetiologies & & \\
Hemorrahge & 189 & 32,87 \\
Hyper tension & 145 & 25,22 \\
Thromboembolic deseases & 5 & 0,87 \\
Infection & 48 & 8,35 \\
Abortions & 33 & 5,74 \\
obstetrical procedures complications & 22 & 3,83 \\
Indirect aetiologies & & \\
Anemia & 31 & 5,39 \\
Cardiac disease & 4 & 0,70 \\
\hline
\end{tabular}

\begin{tabular}{lll}
\hline Cause of death & Number $(\mathbf{N})$ & Percentage (\%) \\
\hline Pulmonary disease & 9 & 1,57 \\
Drepanocytosis & 5 & 0,87 \\
VIH/SIDA & 6 & 1,04 \\
others* & 39 & 6,78 \\
Unknown aetiologies & 39 & 6,78 \\
Total & 575 & 100,00 \\
\hline
\end{tabular}

\section{Discussion}

\subsection{Frequency}

The majority of deaths occurred at the CNHU-HKM maternity unit $(79.30 \%)$. This frequency can be explained by 
its status as a reference hospital and the biggest in Benin. Amoussou [4] in his study done in only the maternity unit of CNHU in 2018 over a period of one (01) year from 2015 to 2017 had found a proportion of $34.44 \%$.

\subsection{Epidemiological Profil}

The most represented age groups in the study were respectively $25-29$ years $(25.57 \%)$ and $30-34$ years $(22.78 \%)$. These results are comparable to those obtained by Thiam et al. [5] in Senegal. A younger age group of 20-24 years was found by Traoré et al [6] in Mali and by Mayi-Tsonga et al [7] in Gabon. This frequency of maternal deaths in this age group can be explained by the fact that these age groups correspond to the period when the pregnancy rate is the highest and linked to maximum fertility. This observation has been made by many authors worldwide [8-10].

Most of the women who died lived in urban areas (66.43\%). Amoussou also made the same observation [4]. The three health facilities are located in the city of Cotonou, the economic capital of Benin.

The majority of the women who died were traders $(40.00 \%)$. The majority of their spouses were workers $(23.65 \%)$. Trade is indeed a widespread occupation in the city of Cotonou, which is also the economic capital. According to the DHS V (2017-2018), among women aged $15-49$, the majority was employed in trade (46\%).

Among men, it is agriculture that occupies the first place (45\%), followed by trade (19\%) and industry (11\%) [3]. These are professions that do not provide a fixed income in a context where health costs are borne by families who are sometimes unable to pay them.

\subsection{Clinical Profil}

Maternal deaths occurred much more among pauciparous women (33.57\%). Barry [11] in Senegal also found a preponderance of pauciparous women followed by large multiparous women. Foumsou et al [11] in TChad found a preponderance of primiparous women. Numerous studies have shown that multiparity is associated with a greater risk of maternal death $[12,13]$. All pregnant women, regardless of their parity, are therefore subject to the risk of maternal death.

In this study, $78.96 \%$ of the women who died were referred. Amoussou [4] found a similar result at CHNUHKM. Furthermore, among the deceased women, 58.43\% had an altered general status and while considering only the referred population, this proportion increases to $62.99 \%$ of cases. In fact, for various reasons, the reference hospital most often receive patients as a last resort, after the onset of sometimes irreversible complications. The same observation has been made by other authors elsewhere [5, 14].

Although the majority of patients were admitted in the prepartum period, the majority of maternal deaths occurred in the post-partum period $80.17 \%$. This is clearly a critical period for women. The results obtained by Thiam et al [5] and Amoussou [4] also noted a greater number of maternal deaths during the post-partum period. Obstetricians most of the time proceed with delivery to optimise maternal management, especially as these patients are admitted after fetal maturity has been acquired.

In the study, direct obstetric causes were responsible for $76.88 \%$ of maternal deaths. Haemorrhage was the most frequent direct cause $(32.87 \%)$, followed by hypertensive disorders during pregnancy $(25.22 \%)$. Then came infections $(8.35 \%)$ and finally abortions $(5.74 \%)$. Direct obstetric causes have been described by several authors [15-18] as the primary cause of maternal death.

Haemorrhage is the leading cause of maternal death in developing countries, particularly in Africa [18, 19]. For Thiam et al. [5] in Senegal, Yambaré and Ibemba [20] in Congo, Cissé et al [21] in Senegal, haemorrhage was responsible for $42.7 \%, 41.1 \%$ and $30 \%$ of maternal deaths. In the majority of cases, post-partum haemorrhage was the main cause, as in the current study, where it represented 59.25\%. Fenomanana et al [22] in Madagascar and Sépou et al [23] in Bangui found lower proportions of $31.48 \%$ and $30 \%$ respectively.

Hypertensive disorders during pregnancy were the second most common direct obstetric cause, with eclampsia accounting for $66.21 \%$, followed by pre-eclampsia (24.83\%). In the population as a whole, eclampsia and pre-eclampsia together accounted for $22.96 \%$ of maternal deaths. The results obtained by Thiam et al [5] are comparable to those in this study (28.29\%). Some studies rank eclampsia as the leading cause of death in the prepartum period (nearly $25 \%$ of cases) and the second leading cause of death in the postpartum period (just over 20\%) [11, 24, 25].

The indirect obstetric causes found in the study were anaemia $(5.39 \%)$ and HIV infection and were incriminated in about a quarter of the causes of maternal death. According to Yambaré and Ibemba [20] in Congo in 2017, HIV infection was the leading cause, followed by anaemia and heart failure. A high proportion of pregnant women in developing countries suffer from iron deficiency, thus favouring the development of severe iron deficiency anaemia [26]. Regarding HIV infection, sub-Saharan Africa has a high proportion of HIV/AIDS-related maternal deaths at $6.4 \%$ [18]. HIV-infected pregnant women are two to three times more likely to die during delivery or the postpartum period compared to other uninfected women [27]. In this study, 06 out of 21 patients with HIV/AIDS died, i.e. $28.57 \%$.

\section{Limitations}

Incompleteness of information: the files of deceased women did not always contain all the information useful for our study.

\section{Conclusion}

Maternal mortality remains high in our health facilities. It mainly affects populations with modest socio-economic conditions. Reduction requires an improvement in the socio- 
economic conditions of the populations, the technical platform and the referral modalities.

\section{References}

[1] Alkema L, Chou D, Hogan D, Zhang S, Moller A-B, Gemmill $\mathrm{A}$, et al. Global, regional, and national levels and trends in maternal mortality between 1990 and 2015, with scenariobased projections to 2030: a systematic analysis by the UN Maternal Mortality Estimation Inter-Agency Group. The Lancet. 30 Jan 2016; 387 (10017): 462-74.

[2] United Nations. Report on the sustainable development goals 2019. New York: United Nations; 2019 pp. 64. Report No.: 19-06517.

[3] National Institute of Statistics and Economic Analysis (INSAE) and ICF. 2019. Benin Demographic and Health Survey, 20172018. Cotonou, Benin and Rockville, Maryland, USA: INSAE and ICF.

[4] Amoussou R, Vissoh Ayadji A, Acakpo S, Zountcheme S, Hounkpe E, Koukoui N. Yearbook of health statistics. 2016. $165 \mathrm{p}$.

[5] Thiam M, Faye Dieme M, Gueye L, Niane S, Niang M, Mahamat S, et al. Maternal mortality at the Centre Hospitalier Régional de Thiès: etiologies and determining factors, about 239 deaths. J SAGO Gynaecology - Obstetrics Health Reprod [Internet]. 2017 [cited 13 Jul 2020]; 18 (1). Available from: http://jsago.org/index.php/jsago/article/view/3.

[6] Traoré B, Thera T, Kokaina C, Beye S, Mounkoro N, Teguete I, et al. Maternal mortality in the gynecology-obstetrics department of the regional hospital of Segou in Mali retrospective study on 138 cases. Mali Médical. 2010; 25 (2): 42-7.

[7] Mayi-Tsonga S, Ndombi I, Oksana L, Methogo M, Diallo T, Mendome G, et al. Maternal mortality in Libreville (Gabon): status and challenges in 2006. Cah Détudes Rech Francoph Santé. 2008; 18 (4): 193-7.

[8] Penfold F, Harrison E, Bell J, Fitzmaurice A. Evaluation of delivery fee exemption policy in Ghana: population estimates of changes in delivery service utilisation in two regions. Ghana medical journal 2007; 41 (3): 100-9.

[9] Traore B, Kokaina C, Beye Sa, Traore M, Dolo A. Caesarean section in the hospital centre of Ségou in Mali. Médecine d'Afrique noire $\mathrm{N}^{\circ}$ 5711. November 2010. P513-518.

[10] Jean Dupont Kemfang Ngowa, Anny Ngassam, Jovanny Tsuala Fouogue, Junie Metogo, Alexis Medou, Jean Marie Kasia. Early maternal complications of caesarean section: about 460 cases in two university hospitals in Yaoundé, Cameroon. Pan African Medical Journal. 2015; 21: 265 doi: 10.11604/pamj.2015.21.265.6967.

[11] Foumsou L, Saleh A, Kaïmba O. Determinants of maternal mortality in the National General Reference Hospital of N'Djamena-Chad. Revue Scientifique du Tchad. 2014; 1 (5): 35-41.

[12] Alves SV. Maternal mortality in Pernambuco, Brazil: what has changed in ten years? Reprod Health Matters. 2007; 15 (30): 134-44.
[13] Philibert M, Boisbras F, Bouvier-Colle M-H. Epidemiology of maternal mortality in France from 1996 to 2002: frequency, factors and causes. Bull Epidémiologique Hebd - BEH. 2006; (50): 392-5.

[14] Coppieters Y, Bivort P, Madani K, Metboul M. Analysis of the factors of maternal mortality in southern Algeria. Sante Publique (Bucur). 25 Nov 2011; Vol. 23 (5): 413-26.

[15] WHO, World Health Organization. Maternal mortality [Internet]. [cited 12 Jul 2020]. Available from: https://www.who.int/fr/news-room/fact-sheets/detail/maternalmortality.

[16] Perrin R. Maternal Mortality in the World. Proj Mère-Enfant Ministère Étrangères Eur. 2008.

[17] Fomulu FJ, Ngassa PN, Nong T, Nana P, Nkwabong E. Maternal mortality at the Maternity Hospital of the Centre Hospitalier et Universitaire de Yaoundé, Cameroon: a 5-year retrospective study (2002 to 2006). Health Sci Dis. 2013; 10 (1).

[18] Veronique F, Doris C, Carine R, Wendy G, Say L. Level and Causes Maternal Mortality and Morbidity. Reproductive, Maternal, Newborn, and Child Health. Level Causes Matern Mortal Morb Reprod Matern Newborn Child Health. 2016; 51-70.

[19] Dujardin B, Mine F, De Brouwere V. Improving maternal health: a guide for systemic action. L'Harmattan; 2014. 303 p.

[20] Yambare A, Ibemba G. Analysis of the determinants of Prepartum Maternal Mortality in the Republic of Congo (20132015). 2017.

[21] Cissé ML, Raad B, Diouf A, Wade F, Moreau JC. Assessment of obstetrical evacuations at the regional hospital of Kolda (Senegal). Médecine Afr Noire. 2010; 57 (1): 37-43.

[22] Fenomanana MS, Riel AM, Rakotomena SD, Andrianjatovo JJ, Andrianampanalinarivo HR. Risk factors for postpartum hemorrhage mortality at the Maternité de Befelatanana-CHU Antananarivo-Madagascar. Rev D'anesthésie-Réanimation Médecine D'urgence. 2009; 1 (3): 4-7.

[23] Sépou A, Yanza MC, Nguembi E, Dotte GR, Nali MN. Analysis of medical evacuations in gynaecology-obstetrics in Bangui, Central African Republic. Cah Détudes Rech Francoph. 2001; 10 (6): 399-405.

[24] Schutte JM, Steegers E a. P, Schuitemaker NWE, Santema JG, de Boer K, Pel M, et al. Rise in maternal mortality in the Netherlands. BJOG Int J Obstet Gynaecol. March 2010; 117 (4): 399-406.

[25] Schuitemaker N, van Roosmalen J, Dekker G, van Dongen P, van Geijn H, Gravenhorst JB. Confidential enquiry into maternal deaths in The Netherlands 1983-1992. Eur J Obstet Gynecol Reprod Biol. 1998; 79 (1): 57-62.

[26] Bouvier-Colle M-H ne, Ouedraogo C, Dumont A, Vangeenderhuysen C, Salanave B, Decam C. Maternal mortality in West Africa: rates, causes and substandard care from a prospective survey. Acta Obstet Gynecol Scand. 2001; 80 (2): 113.

[27] Lathrop E, Jamieson DJ, Danel I. HIV and maternal mortality. Int J Gynaecol Obstet off Organ Int Fed Gynaecol Obstet. Nov 2014; 127 (2): 213-5. 